\title{
A Walk in Our Shoes: A Discussion of Relevance and Communication in Teacher Prep
}

\author{
Karen L. Goldman* Ph.D., Melanie Cardell Ph.D. \\ University of the Cumberlands, Williamsburg, KY \\ *Corresponding Author: karen.goldman@ucumberlands.edu
}

Copyright (C) 2013 Horizon Research Publishing All rights reserved.

\begin{abstract}
Relevance is discussed in light of $21 \mathrm{st}$ c. communication skills and relevance. How do these areas impact both the face-to-face and online candidates in the MAT and MAED programs to positively impact P-12 students? Relevance theory and communication in $21 \mathrm{st} \mathrm{c}$. is clarified for working in both face-to-face and online learning environments leading current and future teachers into needed skills for education and specifically literacy. The authors offer their insights including anecdotal evidence from current successful practices.
\end{abstract}

Keywords Online Learning, Epistemology, Communication

\section{Introduction}

Relevance is important to communication. Communication is crucial for good teaching. Communication forms have changed, but has relevance changed for the $21^{\text {st }}$ century? How do the areas of relevance and communication impact the online professors and candidates in MAT and MAED programs leading to a positively impact P-12 students? These are the driving questions that came to us as our graduate programs exploded with enrollment during 2012. We teach at the University of the Cumberlands in Williamsburg, Kentucky. The original role of the institution was to reach into the hills of Appalachia and make a difference in the lives of its people. To this day, many of our students both undergraduate and graduate are the first to complete high school much less a college degree. Our insights come from the levels of undergraduate and graduate courses currently taught to future and current teachers.

Relevance Theory and communication concerns for $21^{\text {st }} \mathrm{c}$ students are driving concepts for our work in an online learning environment. While the environment has changed from brick and mortar to cyber-classroom, the goals are the same, developing current and future teachers' skills in education, specifically literacy. Connecting these concepts for online university faculty necessitates the milieus of the P-12 environment in both the classroom and in teacher-colleague communication, as well as the virtual university environment. We seek to mesh congruently and seamlessly. Technology developments drive the needs and become transparent for the candidates and the professors as both teach and learn simultaneously.

\section{Does Communication Differ in Online from Face-to-Face Teaching? Redefining Relevant Communication for Instruction}

What is relevant communication? How can online instruction assure relevance? The concept of relevance relates to many different fields, especially that of epistemology (the theory of knowledge). To define relevant communication, let us first look at Relevance theory. Relevance theory is a psychological theory proposed by Dan Sperber and Deirdre Wilson (Sperber \& Wilson 1985, 1995) that seeks to explain the second method of communication, implicit inferences. The first method of communication is direct speaking. When we arrive at a conclusion based on the premise of what is known or assumed to be true, we are making an inference. Inferences may be explicit or implicit; implicit is implied or unquestioned.

Relevance Theory argues that the hearer/reader/audience searches for meaning in any given communication. Having found meaning that fits their expectation [of relevance, the hearer/reader/audience processing] the communication is complete and valued. If the hearer does not find an anchor for meaning it may become like a leaf falling from a tree in autumn, just another thought not retained. As a teacher this unprocessed or misinterpreted thought leads to a lack of understanding and often miscommunications.

Having laid some ground work in communication, undergraduate students in a middle school teacher prepcourse were pushed to refine their concepts of diversity and literacy. To set up the learning activity, each fall semester the students come to class and are immediately asked to take 10 minutes to go outside and bring in 3-5 different leaves. The leaves, a metaphor for diversity in middle schools, serve as the thought conduit. Filtering through the multiple experiences, the existing variations are intriguing. Our campus lies in the southern Appalachians of 
eastern Kentucky and has some of the greatest tree diversity in the country. [It is interesting to note that in contrast with this diversity, the geographic region lacks diversity in races and ethnicities.] The students return to the classroom, chattering happily, carrying their leaves.

The leaves take center stage on a long table, students circling around. Year after year, the students automatically begin arranging the leaves into categories.(In a moment, the students learn that we as humans seek to create order where there is perceived chaos).Waiting and watching as they arrange and rearrange the leaves, I remind myself to also talk about the human mind's natural inclination for patterns, Sense-making theory. The questions begin:

"What are you doing?" I ask.

"We are arranging the leaves!"

"Why? [Pause for effect]. Do you know what the leaves represent?"

After this question, the students look puzzled. No, they had no idea. It is at this moment that the discussion begins about diversity. The students are asked to select a leaf that represents them.

Setting the example, my leaf is chosen. It is tall and somewhat unattractive. As the discussion begins, I mention that my chosen leaf represents me as a middle schooler. One tall young lady chooses a medium size Maple leaf with a very long stem. She states that she was too tall with a head of fluffy hair. A young man chooses a yellowing Poplar leaf with a few spots and a tear. He states that he was stout with blond hair and rough around the edges. With this personal connection comes the personification of leaves as middle schoolers reaching the second stage of relevance.

To clarify, this second stage of relevance affects the audience, any audience. This example contrasts relevance theory with a conduit metaphor. The conduit in the class is the leaves. These leaves take on the persona of middle schoolers. In this conduit metaphor the communication consists of a sender (me), a message (how), and a receiver (students). When we communicate, it likely occurs in one of two ways. Communicating from one person to another using code or the Conceptual Model that takes into account the context of the communication.

The Code Model is commonly seen in Morse Code using strict coding and decoding. In this approach the speaker/author encodes their thoughts and transmits them to the audience. The audience receives the encoded message and decodes it arriving at the intended meaning of the speaker/author: Speaker's thought/intention $\Rightarrow$ encoded $\Rightarrow$ transmitted $\Rightarrow$ decoded $\Rightarrow$ intention/thought understood. Human communication, however, is rarely so simple. Context almost always plays a part in communication as well as other factors like the author's intentions, the relationship between the sender and receiver, etc. In contrast, the Conceptual Model takes into account the context of the communication and the mutual cognitive environment between the author and the audience. (This can get confusing since what the author/speaker thinks the audience already knows can be wrong leading to misunderstandings). The Conceptual Model uses a minimum of communication, only what is intended. Abbreviating communication relies on the audience to fill in details not explicitly communicated: Speaker's thought/intention $=$ context-mediated information $\Rightarrow$ encoded $\Rightarrow$ transmitted $\Rightarrow$ decoded $=$ context-mediated information $\Rightarrow$ thought/intention understood by hearer (interpretive resemblance to intent). As a teacher this becomes a common experience, students who do not understand the directions.

How is it that the simple act of leaf collecting becomes organizing and representing middle school students? What mental constructs allow or cause this to occur? This leaf exercise represents the second form of communication, inference. To infer, one must deduce, make presumptions based on their knowledge. It uses deductive reasoning, making decisions based on assumptions of facts. Having primed the students with ground work in communication, they were pushed to refine their concepts of diversity and literacy. This gathering and analyzing of the leaves proves the students degrees of interpretation and inference. They each consistently choose a leaf that reflects the view of self in middle school thus proving the use of personal experience filter.

\section{Relevance, Communication, and Community in Online Classes}

The leaf experience is a face-to-face activity. How can clear communication occur with online students? Going back to Relevance Theory (Sperber and Wilson), it begins with assumptions that are typical of pragmatic theories arguing that all utterances are heard within the context of the hearer. Utterances in general convey a number of implications. In addition, they posit the notion of manifestness that is grasped either consciously or unconsciously by a person. The core of the theory is the communicative principle of relevance.

This Relevance Theory states that the act of making an utterance (the speaker) conveys that what is said is worth listening to thus providing cognitive effects worthy of the processing. It is from the act of processing that meaning is found thus, every ostensive act of communication has lexical clues explicitly conveyed. How does this take place in an online virtual classroom? There are a minimum of two steps in every act of communication: intention and interpretation. Being professors of education, it is vitally important to stress our intention. Intentionally, the course outlines reflect best practices, our best practices. Best teaching practices include such areas as the learning environment, motivating students, and valuing theirdiversity. Student acceptance for their learning is crucial in graduate studies and especially in online courses. Unlike many online programs, we have a virtual class time to manage. This then brings us back to the two steps in communication.

- The speaker purposefully gives a clue to the hearer, ("ostensifies"), as to what $\mathrm{s} / \mathrm{he}$ wishes to communicate. That 
is a clue to intention.

This happens through use of presentation programs such as Prezi or Power Point, Youtube videos, etc. The students talk directly with the instructor and their classmates. While we prefer that all students have headphones with microphones, all students discuss using the text box feature.

- The hearer infers the intention from the clue and the context-mediated information. The hearer must interpret the clue, taking into account the context, and surmise what the speaker intended to communicate.

Discussions about the syllabus, learning projects, and class readings fulfill the clarification process. With our combined fifty plus years of teaching, student interpretation continues to be a challenge. Each comes with different experiences filtering any verbal and visual presentations.

Another strategy used is that of Mastery Learning. This concept developed through the work of Benjamin Bloom in the 1970s. As such it is certainly not a new concept, yet surprisingly one unfamiliar with most students. Bloom hypothesized that a classroom using mastery learning closes learning gaps as opposed to the traditional form of instruction thus reducing the achievement gaps between varying groups of students (Guskey 2007). In Mastery learning, "the students are helped to master each learning unit before proceeding to a more advanced learning task" (Bloom 1985). This concept has little to nothing to do with specific content, but rather is a description of the process of mastering particular learning objectives. One example to illustrate is that the students complete a learning project to their level of understanding. It will not be perfect for various reasons. It is graded, found wanting, and returned. The students then have a brief time to reflect on their errors making corrections to their level of understanding. Ideally this continues until their learning is complete or as time allows. The important concept is that students are not judged with a pass/fail, but learning continues, as it should, over time with incremental development. This helps students learn more, at a higher level, and with the students able to implement this learning.

\section{Building Community}

To conclude, communication must be carefully developed. Technology has many tools available yet it is the responsibility of both the professors and students to use them effectively. Win this $21^{\text {st }}$ century, most students have basic computer skills, yet the online course applications vary widely. It is important to have a rigorous program that encourages the skills of all users and to develop the concept of a learning community. A learning community being defined as a group of people who share common values or beliefs and are actively engaged in learning together. This develops through each instructor's approach.

Communication is the key. Our course management system called iLearn has various tools to use from sending mass emails, creating blogs, wikis, or other self-reporting tools. As stated previously, the students attend an actual class known as synchronous learning. They "talk" using a written feature called CHAT inside Elluminate Live!,or they may actually talk with each other using microphones. Questions are asked or answered; ideas and theories discussed building a sense of rapport. Beginning each class with something humorous or personal helps build a learning community and a personal touch. Events are shared in both words and pictures.

Our students are literally from around the world although most are from Kentucky. With the freedom of the internet, students often attend classes while away from home at conferences, from cruise ships, on honeymoons, and even from a hospital room. Recently, candidates shared in one course that their child had taken their first steps, a husband had a new job, and that their new technology skills have led to a better job. Sadly, one candidate clicked the away button to answer the door bell only to be served with divorce papers. The other candidates rallied to her statement of shock with words of support and encouragement. This illustrates that both the highs and lows of daily life are shared in the synchronous sessions. Communication skills are honed and knowledge gained.

\section{REFERENCES}

[1] Dervin, B. (1983). An overview of sense-making research: Concepts, methods and results. Paper presented at the annual meeting of the International Communication Association. Dallas, TX.

[2] Guskey, T.R. (2007). Closing Achievement Gaps: Revisiting Benjamin S. Bloom's "Learning for Mastery. Journal of Advanced Academics. 19, 8-31.

[3] Sperber, D.(2013). Episteme, v.10, no. 1, pgs. 61-71. In Reply to Michael Lian, Kourken, 2013; The evolution of testimony: Receiver of vigilance, speaker honesty, and the reliability of communication. Available: October 10,2012.Online:http://w ww.dan.sperber.fr/wp-content/uploads/Reply-to-Michaelian. pdf

[4] Wilson, D. and D. Sperber (1995).Available: October 12, 2012.Online:

http://people.bu.edu/bfraser/Relevance\%20Theory\%20Orien ted/Sperber\%20\&\%20Wilson\%20-\%20RT\%20Revisited.pdf 